\title{
Histopathological Changes of the Gills Induced by a Group of Amphoteric Surfactants in the Common Carp
}

\author{
Termpong Wayusuwanwit and Hiroshi Kawatsu \\ Division of Fish Pathology, Faculty of Agriculture, Miyazaki University, Gakuen-Kibanadai, Miyazaki 889-21, Japan \\ (Received August 12, 1994)
}

The histopathological effects of a homologous series of amphoteric surfactants, $\mathrm{N}$-alkyl $\left(\mathrm{C}_{8}-\mathrm{C}_{18}\right)$ $\mathrm{N}, \mathrm{N}$-dimethyl-3-ammonio-1-propane sulfonate, on the gills of common carp Cyprinus carpio were examined by light microscopy. Fish were exposed to the lethal concentration $\left(96-\mathrm{h} \mathrm{LC}_{50}\right)$ of each surfactant for $96 \mathrm{~h}$. The gills exposed to $\mathrm{C}_{8}$ showed slight hypertrophy of epithelial cells and epithelial lifting of the secondary lamellae. Marked epithelial lifting was observed after the exposure to $C_{10}$. In the groups exposed to $C_{12}, C_{14}$, and $C_{16}$, hyperplasia between the secondary lamellae occurred to such an extent that it led to lamellar fusion. In the gills exposed to $C_{18}$, hyperplasia was more advanced and revealed fusion of the primary lamellae. These findings suggest that the extent of gill damage induced by this homologous series of amphoteric surfactants progressively deteriorated with the increase in the number of carbon atoms in the alkyl chain.

Key words: common carp, surfactant, toxicity, gill

Gill damage is the most obvious acute toxic effect caused by surfactants. Schmid and Mann ${ }^{1)}$ examined the gill damage induced by dodecylbenzene sulfonate in rainbow trout and described various kinds of histological alterations; swelling of epithelial cells, adhesion of secondary lamellae, detachment of epithelium from the pillar cell system, discharge of mucous cells and haematomas. Abel and Skidmore ${ }^{2)}$ and Abel $^{3)}$ examined the histological changes of the gill after exposure to sodium lauryl sulfate in rainbow and brown trout and reported that the gill epithelium lifts away from the underlying tissue, and that a large number of epithelial cells are sloughed off, but that puncture of the epithelium does not occur. These histological studies dealt with one detergent, and there has been no comparative study on the gill damage induced by surfactants that have different molecular structures. In the present study, we compared the gill alterations caused by a homologous series of amphoteric surfactants, $\mathrm{N}$-alkyl $\left(\mathrm{C}_{8}-\mathrm{C}_{18}\right)-\mathrm{N}, \mathrm{N}$ dimethyl-3-ammonio-1-propane sulfonate, using common carp Cyprinus carpio.

\section{Materials and Methods}

\section{Test Chemicals}

The homologous series of the amphoteric surfactant N-alkyl-N,N-dimethyl-3-ammonio-1-propane sulfonate (alkyl sulfobetaine) has the general formula $\mathrm{C}_{n} \mathrm{H}_{2 n+1}\left(\mathrm{CH}_{3}\right)_{2} \mathrm{~N}\left(\mathrm{CH}_{2}\right)_{3} \mathrm{SO}_{3}$, where $n$ is the number of carbon atoms in the alkyl chain. The surfactants having carbon atoms between 8 and 18 described below were tested. They were all approximately $98 \%$ pure (Sigma Chemical Co., USA).

N-octyl-N, N-dimethyl-3-ammonio-1-propane sulfonate $\left(\mathrm{C}_{8}, \mathrm{FW}=279.4\right)$

$\mathrm{N}$-decyl-N,N-dimethyl-3-ammonio-1-propane sulfonate $\left(\mathrm{C}_{10}, \mathrm{FW}=307.5\right)$

$\mathrm{N}$-dodecyl-N,N-dimethyl-3-ammonio-1-propane sulfonate
$\left(\mathrm{C}_{12}, \mathrm{FW}=335.5\right)$

$\mathrm{N}$-tetradecyl-N,N-dimethyl-3-ammonio-1-propane sulfonate $\quad\left(\mathrm{C}_{14}, \mathrm{FW}=363.6\right)$ $\mathrm{N}$-hexadecyl-N,N-dimethyl-3-ammonio-1-propane sulfonate $\left(\mathrm{C}_{16}, \mathrm{FW}=391.7\right)$ $\mathrm{N}$-octadecyl-N,N-dimethyl-3-ammonio-1-propane sulfonate

$\left(C_{18}, F W=419.7\right)$

\section{Experiment}

Fingerlings of common carp weighing $0.6-0.8 \mathrm{~g}$ were used. The acute toxicity test was carried out under renewal-static conditions in $2-l$ glass beakers containing $1.5 \mathrm{l}$ of test solutions with continuous aeration. Dechlorinated tap water $\left(\mathrm{pH} 7.2\right.$; hardness $52 \mathrm{mg} / l$ as $\mathrm{CaCO}_{3}$ ) was used for this experiment. According to the results of a previous study, ${ }^{*} 10$ randomly selected fish were exposed for $96 \mathrm{~h}$ to each surfactant at the following 96-h LC $\mathrm{L}_{50}$ concentrations; $C_{8}: 59.6, C_{10}: 7.14, C_{12}: 0.49, C_{14}: 0.022, C_{16}: 0.0019$, and $\mathrm{C}_{18}: 0.0010 \mathrm{~mm}$. The test solutions were renewed every day and the water temperature was maintained at $25 \pm 1^{\circ} \mathrm{C}$. The test fish were not fed during the test peroid.

\section{Histological Examination}

Three surviving fish were scarified at the end of the experiment in each group. Fish gills were fixed in Bouin's fixative, embedded in paraffin wax, cut into $4 \mu \mathrm{m}$ thick sections and stained with hematoxylin-eosin according to the standard procedures for light microscopic observation.

\section{Results}

Table 1 summarizes the results of histopathological observations. No recognizable changes were observed in the gills in the control fish (Fig. 1). One of the fish exposed to $C_{8}$ showed slight hypertrophy of epithelial cells and epithelial lifting of the secondary lamellae (Fig. 2). In the group exposed to $C_{10}$, the epithelial layer was separated 
Table 1. Histopathological changes of the gills in common carp induced by a group of amphoteric surfactants, N-alkyl-N,N-dimethyl-3-ammonio-1-propane sulfonate

\begin{tabular}{|c|c|c|c|c|c|}
\hline Surfactant & Sample No. & Epithelial lifting & Hyperplasia & Secondary lamellar fusion & Primary lamellar fusion \\
\hline \multirow[t]{3}{*}{ Control } & 1 & - & - & - & - \\
\hline & 2 & - & - & - & - \\
\hline & 3 & - & - & - & - \\
\hline \multirow[t]{3}{*}{$\mathrm{C}_{8}$} & 1 & \pm & - & - & - \\
\hline & 2 & \pm & + & + & - \\
\hline & 3 & \pm & - & - & - \\
\hline \multirow[t]{3}{*}{$\mathrm{C}_{10}$} & 1 & + & - & - & - \\
\hline & 2 & + & - & - & - \\
\hline & 3 & + & - & - & - \\
\hline \multirow[t]{3}{*}{$C_{12}$} & 1 & + & + & + & - \\
\hline & 2 & - & + & + & - \\
\hline & 3 & + & + & + & - \\
\hline \multirow[t]{3}{*}{$\mathrm{C}_{14}$} & 1 & - & + & + & - \\
\hline & 2 & + & + & + & - \\
\hline & 3 & - & + & + & - \\
\hline \multirow[t]{3}{*}{$\mathrm{C}_{16}$} & 1 & - & + & + & - \\
\hline & 2 & - & + & + & - \\
\hline & 3 & - & + & + & - \\
\hline \multirow[t]{3}{*}{$\mathrm{C}_{18}$} & 1 & - & + & + & + \\
\hline & 2 & - & + & + & + \\
\hline & 3 & - & + & + & + \\
\hline
\end{tabular}

+ : mostly observed, \pm : partially observed, - : not observed.

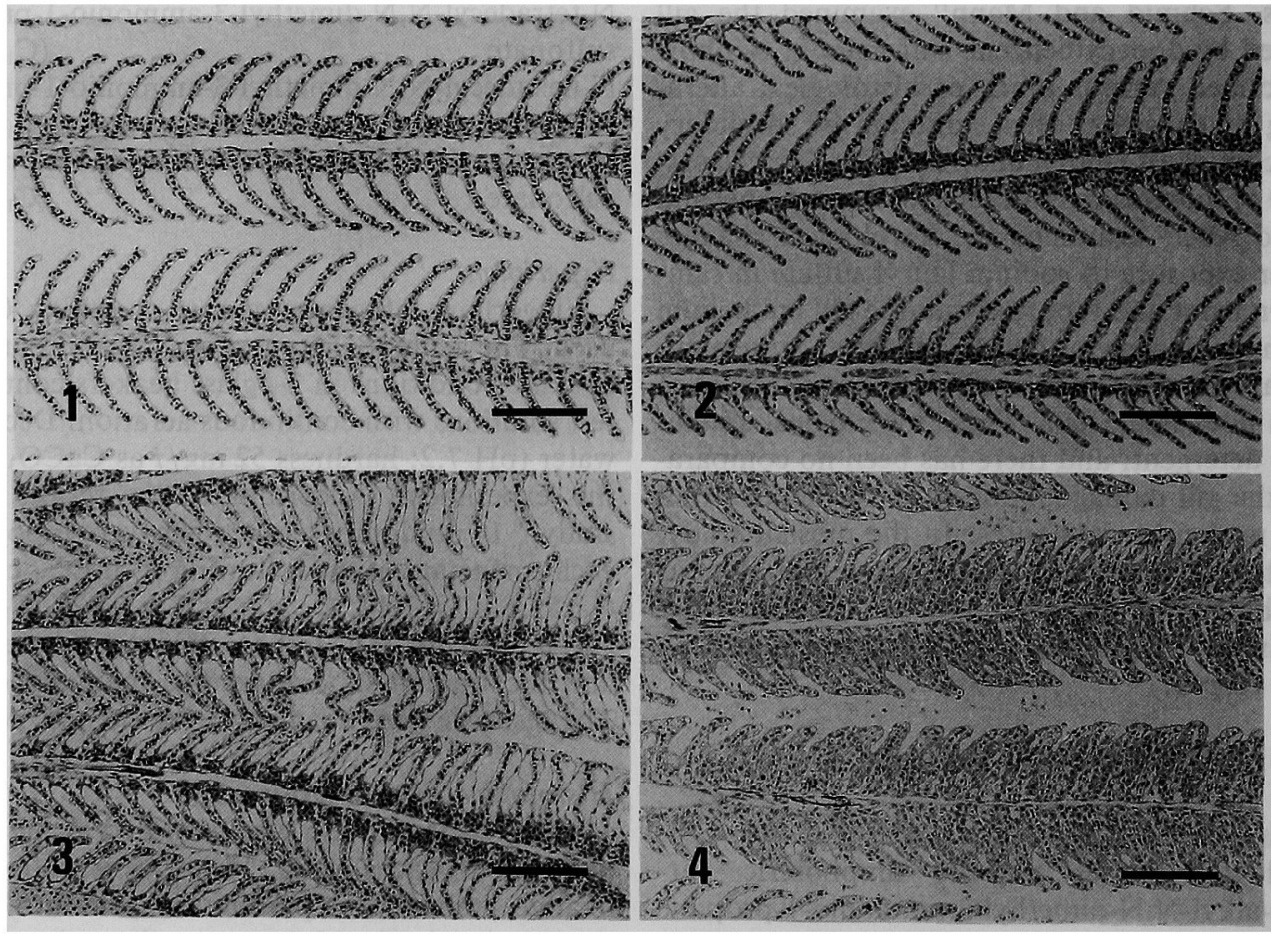

Fig. 1. Secondary gill lamellae of the control fish, not showing any recognizable changes. H\&E staining. Bar, $100 \mu \mathrm{m}$.

Fig. 2. Secondary gill lamellae after exposure to $C_{8}$ surfactant, showing slight hypertrophy of epithelial cells and lifting of the secondary lamellae. H\&E staining. Bar, $100 \mu \mathrm{m}$.

Fig. 3. Secondary gill lamellae after exposure to $C_{10}$ surfactant, showing severe lifting of the secondary lamellae. H\&E staining. Bar, $100 \mu \mathrm{m}$.

Fig. 4. Secondary gill lamellae after exposure to $C_{12}$ surfactant, showing lifting of the secondary lamellae, hyperplasia, and fusion of secondary lamellae.

H\&E staining. Bar, $100 \mu \mathrm{m}$. 


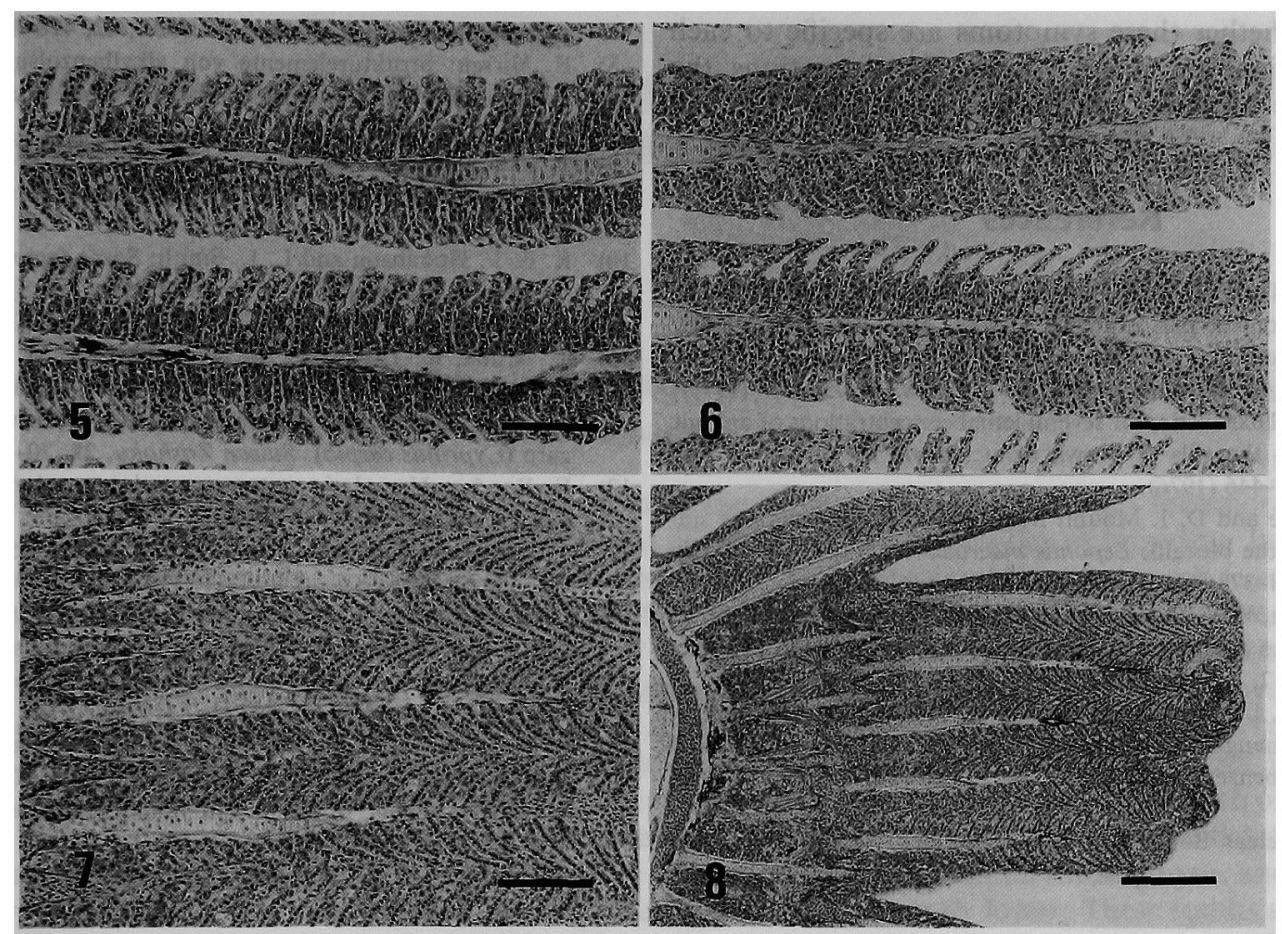

Fig. 5. Secondary gill lamellae after exposure to $C_{14}$ surfactant, showing severe hyperplasia and fusion of the secondary lamellae. H\&E staining. Bar, $100 \mu \mathrm{m}$.

Fig. 6. Secondary gill lamellae after exposure to $C_{16}$ surfactant, showing severe hyperplasia and fusion of the secondary lamellae. H\&E staining. Bar, $100 \mu \mathrm{m}$.

Fig. 7. Secondary gill lamellae after exposure to $C_{18}$ surfactant, showing extensive severe hyperplasia and fusion of the primary lamellae. H\&E staining. Bar, $100 \mu \mathrm{m}$.

Fig. 8. Low magnification of Fig. 7, showing fusion of the primary lamellae. H\&E staining. Bar, $200 \mu \mathrm{m}$.

from the pillar cells (epithelial lifting) which occurred in all individuals (Fig. 3). In the group exposed to $C_{12}$, epithelial lifting was still observed and proliferation of epithelial cells and thickening of the secondary lamellae were observed (Fig. 4). In the groups exposed to $\mathrm{C}_{14}$, and $\mathrm{C}_{16}$, hyperplasia between the secondary lamellae was more advanced to such an extent that it led to lamellar fusion (Figs. 5 and 6). In the group exposed to $\mathrm{C}_{18}$, the interlamellar space was completely occluded and hyperplasia was more advanced and revealed fusion of the primary lamellae (Figs. 7 and 8).

\section{Discussion}

Six surfactants belonging to a homologous series of amphoteric surfactants (alkyl sulfobetaine) produced a wide variety of pathological changes in the gills. Most of these symptoms have been reported by several investigators using other surfactants, ${ }^{1-7}$ with an exception of the primary lamellae fusion occurring in fish exposed to $\mathrm{C}_{18}$. Because gill samples were taken after a $96-\mathrm{h}$ exposure at the $96-\mathrm{h}$ lethal concentrations, the histological changes observed in each group may represent the final stage before death.

Chain length is an important factor in determining surfactant toxicity in fish. The lethal concentration decreases in inverse proportion to the increasing length of the alkyl chain in linear alkylbenzene sulfonate (LAS) ${ }^{8-10)}$ and linear alkyl sulfate. ${ }^{11)} \mathrm{We}^{*}$ obtained similar findings using linear alkyl sulfobetaine used in this study. On the other hand, the in vitro hemolysis test has been applied for the evaluation of cytotoxic activity of surfactants in mammals. ${ }^{12-15}$ We observed that the hemolytic activity of anionic, cationic and amphoteric surfactants also increased in proportion to the increasing length of the alkyl chain ( $T$. Wayusuwanwit and H. Kawatsu: Miyazaki Univ., unpubl. data).

The multiformity of the symptoms of the gill along with the previous findings suggest that the gill damage developed in proportion to the increase in the length of the alkyl chain. However, whether the different symptoms observed among the different groups in this study represent a transient stage of the continuous progress of histological

* Wayusuwanwit, T. and H. Kawatsu: Toxicity of a group of amphoteric surfactants, N-alkyl-N,N-dimethyl-3-ammonio-1-propane sulfonate, to the common carp, Cyprinus carpio, in "Diseases in Asian Aquaculture II"' (ed. by M. Shariff, J. R. Arthur, and R. P. Subasinghe), Fish Health Section, Asian Fisheries Society, Manila, Philippines, 1995 (in press). 
changes, or whether these symptoms are specific to each surfactant remians unknown. To solve these questions, the gill alterations must be examined continuously at short term intervals.

\section{References}

1) O. J. Schmid and H. Mann: Action of a detergent (dodecylbenzene sulphonate) on the gills of trout. Nature Lond., 192, 675 (1961).

2) P. D. Abel and J. F. Skidmore: Toxic effects of an anionic detergent on the gills of rainbow trout. Water Res., 9, 759-765 (1975).

3) P. D. Abel: Toxic action of several lethal concentrations of anionic detergent on the gills of brown trout (Salmo trutta L.). J. Fish Biol., 9, 441-446 (1976).

4) A. E. Lemke and D. I. Mount: Some effects of alkylbenzene sulphonate on the bluegill, Lepomis macrochirus. Trans. Am. Fish. Soc., 92, 373-378 (1963).

5) V. M. Brown, V. V. Miyrovic, and G. T. C. Stark: Effects of chronic exposure to zinc on toxicity of a mixture of detergent and zinc. Water Res., 2, 255-263 (1968).

6) V. Misra, H. Lal, G. Chawla, and P. N. Viswanathan: Pathomorphological changes in gills of fish fingerlings (Cirrhina mrigala) by linear alkyl benzene sulfonate. Ecotox. Environ. Safety, 10, 302308 (1985).

7) S. E. Wendelaar Bonga and R. A. C. Lock: Toxicants and os- moregulation in fish. Nether. J. Zool., 42, 478-493 (1992).

8) E. Hirsch: Strukturelemente von alkylbenzolsulfonaten und ihr einfluss auf das verhalten von fischen. Vom Wasser, 30, 249-259 (1963).

9) P. Lundahl and R. Cabridenc: Molecular structure-biological properties relationships in anionic surface-active agents. Water Res., 12 , 25-30 (1978).

10) K. E. F. Hokanson and L. L. Smith: Some factors influencing the toxicity of linear alkylbenzene sulphonate (LAS) to the blue gill. Trans. Am. Fish. Soc., 100, 1-12 (1971).

11) T. Arima, K. Takahashi, M. Wakabayashi, M. Kikuchi, and T. Kawana: Toxicity of detergents to some aquatic organisms-II. Acute toxicity of anionic surfactants to eggs, larvae and young of carp (Cyprinus carpio). Suisan Zoshoku, 29, 30-37 (1981).

12) E. Ponder: Hemolytic systems containing anionic detergents. J. Gen. Physiol., 30, 15-23 (1947).

13) T. Kondo: Mechanism of hemolysis by surface active agents. $A d v$. Colloid Interface Sci, 6, 139-172 (1976).

14) B. Y. Zaslavsky, N. N. Ossipov, V. S. Krivich, L. P. Baholdina, and S. V. Rogozhin: Action of surface-active substances of biological membranes. II. Hemolytic activity of nonionic surfactants. Biochem. Biophys. Acta, 507, 1-7 (1978).

15) B. Y. Zaslavsky, N. N. Ossipov, and S. V. Rogozhin: Action of surface-active substances of biological membranes. III. Comparison of hemolytic activity of ionic and nonionic surfactants. Biochem. Biophys. Acta, 510, 151-159 (1978). 